\title{
Reply to Giovanna Ferrara
}

\author{
by Richard Hemming
}

Naturally, I expect an actuary not only to be aware of the issue to which I draw attention but also to have toyed with an equally elementary model (probably the discrete time analogue of my own) during training. My paper is not really intended for actuaries. Rather, my aim is to show that the economic assumptions dominate the actuarial in a simplified model of pension scheme funding. The model used should be accessible to those interested in this problem but who have no actuarial training. To most of these the work of an actuary is a complete mystery, and my modest aim is to de-mystify the profession without being misleading. For this reason I emphasise the abstract nature of the model, and do not claim that my main result necessarily carries over to the large pension schemes operating in the UK. The true picture is complicated by many factors which I ignore. However, I would be very surprised if full actuarial calculations were not extremely sensitive to economic assumptions, and if there is even a small probability that these are inappropriately chosen, then the far-reaching implications of this are worthy of attention. I consider a few.

To the extent that Giovanna Ferrara make these points I agree with her comments. But she also refers specifically to the choice of economic assumptions. In particular, she offers me the following piece of advice, expressing surprise that an economist should be guilty of such an elementary error. She suggests, but does not argue, that there is little point in discussing funded pension schemes in a world where real rates of return are negative since there would be little point in this method of financing under such circumstances. I agree that it is widely believed that funding is only worthwhile if real rates of return are positive. However, the arguments that justify funding, and in particular the security motive, apply equally when real rates of return are positive or negative. It has to be remembered that we are discussing company or industry specific schemes here, and not national schemes where the arguments may well be different. In passing, I note there is no suggestion that negative real rates of return cannot be a long-run feature of an advanced economy - this, at least, is encouraging.

In discussing real rates of return, Giovanna Ferrara claims that I boast clairvoyance, while at the same time being pessimistic. I am certainly not clairvoyant, nor am I sure that I would like to be. And if I were, it is not clear to me why I should want to be a pessimist. However, it is clear to me why I would be pessimistic, or at least not very optimistic, in undertaking funding calculations. I do not much like the implications of being more optimistic and mistaken. This does not mean that I would necessarily wish to assume negative real rates of return under current circumstances, but they would be in the feasible set. 
I must admit that comments of the type outlined were not wholly unexpected. I firmly believe that the major elements of actuarial analysis should be more widely understood. It is a pre-requisite of informed discussion amongst all those interested in the problems facing social security and private pension schemes in many countries. However, the simplification necessary to produce a digestible product has its costs. The shortfall from the complexity of full actuarial models is readily assumed to be a deviation from reality that is extended to all aspects of the analysis. Misunderstanding and misinterpretation follow. I fear this may have been my fate. 